\title{
New Smith Internal Model Control of Two-Motor Drive System Based on Neural Network Generalized Inverse
}

\author{
Guohai Liu, Jun Yuan, Wenxiang Zhao, and Yaojie Mi \\ School of Electrical and Information Engineering, Jiangsu University, Zhenjiang 212013, China \\ Correspondence should be addressed to Wenxiang Zhao; zwx@ujs.edu.cn
}

Received 11 November 2015; Accepted 28 January 2016

Academic Editor: Qiao Zhang

Copyright (C) 2016 Guohai Liu et al. This is an open access article distributed under the Creative Commons Attribution License, which permits unrestricted use, distribution, and reproduction in any medium, provided the original work is properly cited.

Multimotor drive system is widely applied in industrial control system. Considering the characteristics of multi-input multioutput, nonlinear, strong-coupling, and time-varying delay in two-motor drive systems, this paper proposes a new Smith internal model (SIM) control method, which is based on neural network generalized inverse (NNGI). This control strategy adopts the NNGI system to settle the decoupling issue and utilizes the SIM control structure to solve the delay problem. The NNGI method can decouple the original system into several composite pseudolinear subsystems and also complete the pole-zero allocation of subsystems. Furthermore, based on the precise model of pseudolinear system, the proposed SIM control structure is used to compensate the network delay and enhance the interference resisting the ability of the whole system. Both simulation and experimental results are given, verifying that the proposed control strategy can effectively solve the decoupling problem and exhibits the strong robustness to load impact disturbance at various operations.

\section{Introduction}

Multimotor drive system is a multi-input multioutput (MIMO), nonlinear, strongly coupled, and time-varying delay system, which has been widely applied in modern industry. High precision coordinated control performance can improve quality and productivity of products, such as electric vehicles and rail transits [1-4]. In order to meet the requirements of industrial applications, the delay problem of the system must be solved, and then the coupling variables of this system can be decoupled.

In a multimotor drive system, decoupling speed and tension is a key issue. Traditional decoupling control methods strongly depend on mathematical model of the system, such as PID control, sliding mode control [5], feed-forward control [6], and adaptive fuzzy control [7]. Moreover, the structure characteristics or parameters are easily influenced by load variation and interference factor. So, it is hard to obtain accurate system mathematical model. A new control strategy based on support vector machine (SVM) theory has been proposed to decouple current and rotational speed of a permanent-magnet (PM) motor system [8]. Recently, neural network generalized inverse (NNGI) is used to decouple strong-coupling controlled variables [9-11]. Torque and flux components of five-phase PM motors were decoupled by multiple-reference-frame transformation, in which the artificial neural network (ANN) controller was trained online to adapt system uncertainties [12]. Based on a single artificial neuron requiring no offline training, an intelligent speed controller for the PM motor was proposed to adapt to various drives without extensive knowledge of motor behavior [13]. Since the analysis model of the traveling-wave ultrasonic motor is difficult to obtain, a generalized regression neuralnetwork-based model is developed to solve the problem and the transfer function identification is no longer required [14]. An ANN-based estimator is implemented to eliminate mechanical sensors and then realize the sensorless control of a PM motor [15]. By using a pseudolinear composite system, NNGI can transform a MIMO nonlinear system into several single-input single-output linear systems, in which an accurate mathematic model is not required.

In addition, the demand of real-time transmission is high because a large transmission delay will result in uncontrollable system in practice. So, an effective control strategy is necessary to implement the delay compensation. Traditional Smith predictor control is an effective method to conquer 
the influence of system delay [16, 17]. However, this control method is sensitive to the errors of estimate model and external disturbance. An inaccurate estimate model or a strong interference will affect control quality and even lead to system instability. According to the strong robustness and anti-interference abilities of internal model control [18], the control structure is widely used in many applications. A strategy based on internal model control was proposed for a matrix converter-based PMSM drive system to reduce the adverse impact on drive performance caused by nonlinear output characteristics of matrix converter in the case of input voltage disturbance [19]. The speed regulation problem for a PM motor drive was settled by a fuzzy adaptive law based internal model control scheme, and the effectiveness of the proposed methods has been verified [20]. An internal model control with a conditional integrator was proposed for the robust output regulation of a DC/DC buck converter [21]. In the work, Smith predictor control is codesigned with internal model control structure, and then the Smith internal model (SIM) control structure is formed. This SIM control incorporates the advantages of both Smith estimate control and internal model control, which can not only reduce the effect of network delay, but also improve the robustness of system. However, since it is hard to obtain the estimate model in multimotor system, the application of SIM control is very limited. On the basis of NNGI method, the accurate model of generalized pseudolinear subsystem will be obtained and the estimate model can be acquired without mismatch. Therefore, the delay compensation can be implemented successfully.

The purpose of this paper is to propose a new control method, namely, NNGI-based Smith internal model (NNGISIM) control, to improve the operating performance of a two-motor drive system. This NNGI-SIM control can avoid the mismatch between prediction model and original model. The theory of NNGI decoupling method is introduced first; then, the two-motor drive system is decoupled by NNGI method; the accurate model of generalized pseudolinear subsystem will be obtained and the mismatch condition will be conquered. After the theory of SIM control is deduced, the NNGI system is structured and codesigned with SIM control strategy to form the new NNGI-SIM control and then applied in two-motor drive system.

The structure of this paper is as follows: in Section 1, the multimotor drive system will be introduced. In Section 2, the mathematical model of two-motor drive system will be deduced. In Section 3, the new NNGI-SIM control will be formed and applied in two-motor drive system. In Sections 4 and 5, decoupling effect and robustness under load disturbance of the proposed two-motor drive will be verified by both simulations and experiments. Finally, conclusions will be drawn in Section 6.

\section{Mathematical Model}

A two-motor synchronous system is shown in Figure 1; it consists of two three-phase asynchronous induction motors, in which motor 1 is the master motor and motor 2 is the slave one. The belt-pulley is installed on the motor shaft, and both motors are combined by transmission belt on the pulley

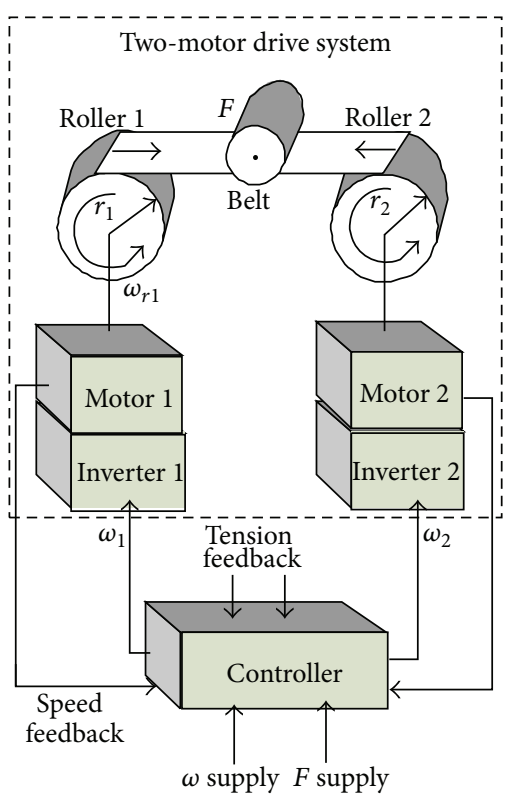

FIgURE 1: Physical model diagram of two-motor drive system.

one. Floating rollers strain the belt to increase the friction between the belt and the driving rollers. Two motors operate synchronously by adjusting the action between speed and tension.

When both motors operate in the vector control mode, the rotor flux is considered to be invariant. Then, the mathematic model of the system can be written as

$$
\begin{aligned}
\dot{\omega}_{r 1} & =\frac{n_{p 1}}{J_{1}}\left[\left(\omega_{1}-\omega_{r 1}\right) \frac{n_{p 1} T_{r 1}}{L_{r 1}} \psi_{r 1}^{2}-\left(T_{L 1}+r_{1} F\right)\right], \\
\dot{\omega}_{r 2} & =\frac{n_{p 2}}{J_{2}}\left[\left(\omega_{2}-\omega_{r 2}\right) \frac{n_{p 2} T_{r 2}}{L_{r 2}} \psi_{r 2}^{2}-\left(T_{L 2}-r_{2} F\right)\right], \\
\dot{F} & =\frac{K}{T}\left(\frac{1}{n_{p 1}} r_{1} k_{1} \omega_{r 1}-\frac{1}{n_{p 2}} r_{2} k_{2} \omega_{r 2}\right)-\frac{F}{T},
\end{aligned}
$$

where $\omega_{i}$ and $\omega_{r i}$ are the synchronous angular speed and the electric angular speed, $F$ is the tension of the belt, $n_{p i}$ is the pole-pairs number of the number $i$ motor, $J_{i}, \psi_{r i}$, and $L_{r i}$ are rotor inertia, rotor flux, and rotor self-inductance, $T_{r i}$ is the electromagnetic time constant, $T_{L i}$ is the load torque, $K=E / v$ is the transfer coefficient, $T=L_{0} / A v$ is the time constant of tension variation, $E$ is Young's modulus of elasticity, $v$ is the expected line speed, $L_{0}$ is the distance between racks, $A$ is the section area, $r_{i}$ is the radius of belt-pulley, and $k_{i}$ is the speed ratio $(i=1,2)$, respectively.

\section{Controller Design}

3.1. NNGI System. Generalized inverse system can realize the inverse mapping relationship from the output to the input of original system. By setting the original order, derivatives and their linear combination of expected output of original system can be used as the input of the generalized inverse 




FIGURE 2: NNGI pseudolinear composite subsystem equivalent chart.

system. Then, the output can be used as the input of original system to drive the original system, generating the expected output [22].

As a MIMO nonlinear system which has $q$-dimensional input vector $u=\left(u_{1}, u_{2}, \ldots, u_{q}\right)^{T} \in R^{q}$ and $q$-dimensional output vector $y=\left(y_{1}, y_{2}, \ldots, y_{q}\right)^{T} \in R^{q}$, the differential equation can be expressed as

$$
F\left(y^{(\varepsilon) T} Y, u^{(\sigma) T}, U\right)=0,
$$

where

$$
\begin{aligned}
\varepsilon & =\left(\varepsilon_{1}, \ldots, \varepsilon_{q}\right)^{T}, \\
\sigma & =\left(\sigma_{1}, \ldots, \sigma_{q}\right)^{T}, \\
y^{(\varepsilon)} & =\left(y_{1}^{\left(\varepsilon_{1}\right)}, \ldots, y_{q}^{\left(\varepsilon_{q}\right)}\right), \\
u^{(\sigma)} & =\left(u_{1}^{\left(\sigma_{1}\right)}, \ldots, u_{q}^{\left(\sigma_{q}\right)}\right), \\
Y & =\left(y_{1}^{\left(\varepsilon_{1}-1\right)}, \ldots, y_{1}, \ldots, y_{q}^{\left(\varepsilon_{q}-1\right)}, \ldots, y_{q}\right)^{T}, \\
U & =\left(u_{1}^{\left(\sigma_{1}-1\right)}, \ldots, u_{1}, \ldots, u_{q}^{\left(\sigma_{q}-1\right)}, \ldots, u_{q}\right)^{T} .
\end{aligned}
$$

$\varepsilon_{j}$ and $\sigma_{j}$ are the highest derivative orders of input $u_{j}$ and output $y_{j}$.

If the relative order of the system $\alpha=\left(\alpha_{1}, \alpha_{2}, \ldots, \alpha_{q}\right)^{T}$ is existent and the sum of relative order $\sum_{j=1}^{q} \alpha_{j}=n$ ( $n$ is the order of the system), the state equation of the system can be transformed into differential equation. Hence, when the relative order is equal to the original order, the generalized inverse of the system can be directly obtained as

$$
u=\bar{\phi}(\bar{Y}, \bar{v}) \text {, }
$$

where

$$
\begin{aligned}
\bar{Y} & =\left(y_{1}, y_{1}^{(1)}, \ldots, y_{1}^{\left(\alpha_{1}-1\right)}, \ldots, y_{q}, y_{q}^{(1)}, \ldots, y_{q}^{\left(\alpha_{q}-1\right)}\right)^{T}, \\
\bar{v} & =\left(\overline{v_{1}}, \overline{v_{2}}, \ldots, \overline{v_{q}}\right)^{T}, \\
\overline{v_{j}} & =a_{j 0} y_{j}+a_{j 1} y_{j}^{(1)}+\cdots+a_{j\left(\alpha_{j}-1\right)} y_{j}^{\left(\alpha_{j}-1\right)}+a_{j \alpha_{j}} y_{j}^{\left(\alpha_{j}\right)} \\
& \quad(j=1 \sim q) .
\end{aligned}
$$

By connecting the generalized inverse system in series, the coupled original system can be decoupled into several generalized pseudolinear composite subsystems and the transfer function of the subsystem can be expressed as

$$
\begin{gathered}
\mathbf{G}(s)=\operatorname{diag}\left(G_{11}(s), \ldots, G_{q q}(s)\right) \\
=\operatorname{diag}\left(\frac{1}{a_{1 \alpha_{1}} s^{\alpha_{1}}+a_{1\left(\alpha_{1}-1\right)} s^{\left(\alpha_{1}-1\right)}+\cdots+a_{11} s+a_{10}},\right. \\
\left.\quad \ldots, \frac{1}{a_{q \alpha_{q}} s^{\alpha_{q}}+a_{q\left(\alpha_{q}-1\right)} s^{\left(\alpha_{q}-1\right)}+\cdots+a_{q 1} s+a_{q 0}}\right) .
\end{gathered}
$$

In practice, the structure of MIMO nonlinear system is complicated and it is hard to obtain its accurate mathematical model. Even if the existence of generalized inverse system has been proved, the expression of generalized inverse of the system cannot be derived for various occasions. To solve this problem, an ANN is used to approximate the original system. This method is independent of the accurate mathematical model, thus enhancing the popularization of inverse system algorithm. The NNGI pseudolinear composite subsystem equivalent chart is shown in Figure 2.

3.2. NNGI Construction for Two-Motor Drive System. According to the mathematic model of two-motor drive system in (1), the existence of generalized inverse system will be proved. Variables are chosen as follows.

State variable is

$$
x=\left[x_{1}, x_{2}, x_{3}\right]^{T}=\left[\omega_{r 1}, \omega_{r 2}, F\right]^{T} ;
$$

control variable is

$$
u=\left[u_{1}, u_{2}\right]^{T}=\left[\omega_{1}, \omega_{2}\right]^{T}
$$

output variable is

$$
y=\left[y_{1}, y_{2}\right]^{T}=\left[\omega_{r 1}, F\right]^{T} .
$$




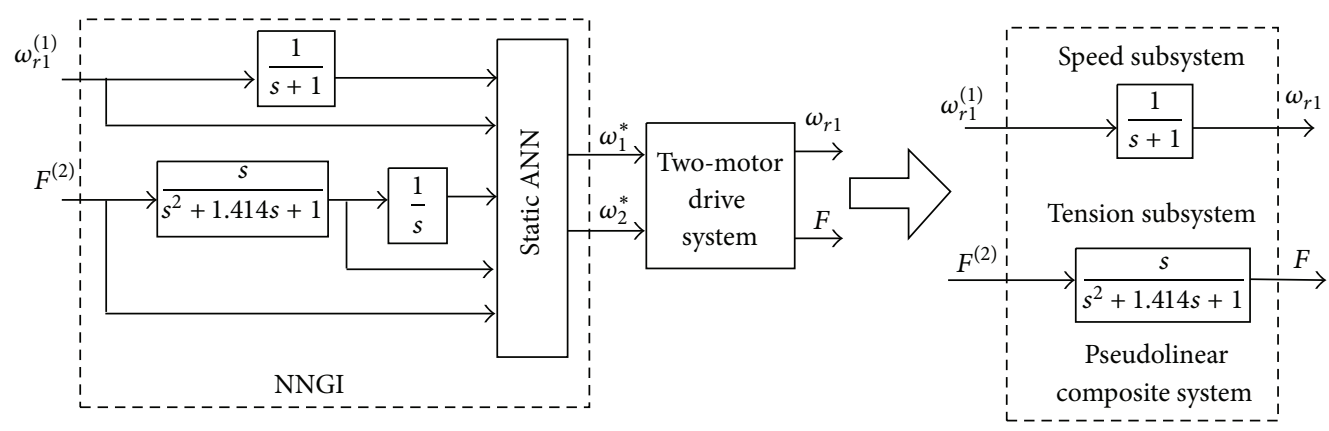

Figure 3: Pseudolinear composite system.

Then, the mathematic model of two-motor drive system can be expressed as

$$
\begin{aligned}
\dot{x} & =f(x, u) \\
& =\left\{\begin{array}{c}
\frac{n_{p 1}}{J_{1}}\left[\left(u_{1}-x_{1}\right) \frac{n_{p 1} T_{r 1}}{L_{r 1}} \psi_{r 1}^{2}-\left(T_{L 1}+r_{1} x_{3}\right)\right] \\
\frac{n_{p 2}}{J_{2}}\left[\left(u_{2}-x_{2}\right) \frac{n_{p 2} T_{r 2}}{L_{r 2}} \psi_{r 2}^{2}-\left(T_{L 2}-r_{2} x_{3}\right)\right] \\
\frac{K}{T}\left(\frac{1}{n_{p 1}} r_{1} k_{1} x_{1}-\frac{1}{n_{p 2}} r_{2} k_{2} x_{2}\right)-\frac{x_{3}}{T}
\end{array}\right\} .
\end{aligned}
$$

According to the generalized inverse theory, the corresponding Jacobi matrix can be described as

$$
\begin{gathered}
J(x, u)=\left[\begin{array}{ll}
\frac{\partial y_{1}^{(1)}}{\partial u_{1}} & \frac{\partial y_{1}^{(1)}}{\partial u_{2}} \\
\frac{\partial y_{2}^{(2)}}{\partial u_{1}} & \frac{\partial y_{2}^{(2)}}{\partial u_{2}}
\end{array}\right] \\
=\left[\begin{array}{cc}
\frac{n_{p 1}^{2} T_{r 1} \psi_{r 1}^{2}}{J_{1} L_{r 1}} & 0 \\
\frac{K r_{1} k_{1} n_{p 1} T_{r 1} \psi_{r 1}^{2}}{T J_{1} L_{r 1}} & -\frac{K r_{2} k_{2} n_{p 2} T_{r 2} \psi_{r 2}^{2}}{T J_{2} L_{r 2}}
\end{array}\right], \\
\operatorname{Det}(J(x, u))=\frac{K r_{2} k_{2} n_{p 1}^{2} n_{p 2} T_{r 1} T_{r 2} \psi_{r 1}^{2} \psi_{r 2}^{2}}{T J_{1} J_{2} L_{r 1} L_{r 2}} .
\end{gathered}
$$

When $\psi_{r 1} \neq 0$ and $\psi_{r 2} \neq 0$, the Jacobi matrix is nonsingular. The relative order of the system is $\alpha=\left(\alpha_{1}, \alpha_{2}\right)=$ $(1,2), \alpha_{1}+\alpha_{2}=3$, and it is equal to the order of the system. In addition, the original order of the system is $n_{e}=\left(n_{e 1}, n_{e 2}\right)=$ $(1,2), n_{e 1}+n_{e 2}=3$, and it is the same as relative order. So, the inverse of the system is existent and can be expressed as

$$
u=\bar{\phi}\left(\left\{y_{1}, \dot{y}_{1}, y_{2}, \dot{y}_{2}, \ddot{y}_{2}\right\}, \bar{v}\right)
$$

where

$$
\begin{aligned}
& \bar{v}=\left(\overline{v_{1}}, \overline{v_{2}}\right)^{T}, \\
& \overline{v_{1}}=a_{10} y_{1}+a_{11} y_{1}^{(1)}, \\
& \overline{v_{2}}=a_{20} y_{2}+a_{21} y_{2}^{(1)}+a_{22} y_{2}^{(2)} .
\end{aligned}
$$

In (12), to keep the stability of the open-loop system, $a_{10}=$ $1, a_{11}=1 ; a_{20}=1, a_{21}=1.414$, and $a_{22}=1$. Then, the transfer function of the subsystem is

$$
\begin{aligned}
G(s) & =\operatorname{diag}\left(G_{11}, G_{22}\right) \\
& =\operatorname{diag}\left(\frac{1}{s+1}, \frac{1}{s^{2}+1.414 s+1}\right) .
\end{aligned}
$$

By connecting the generalized inverse system in series, the original system can be decoupled and simplified into a first-order subsystem and a second-order subsystem. As a result, the composite pseudolinear system is derived and shown in Figure 3.

Simultaneously, by adjusting the parameters $a_{10}, a_{11}, a_{20}$, $a_{21}$, and $a_{22}$, the zeros and poles of pseudolinear subsystems can be developed exactly. Two generalized pseudolinear subsystems have neither right half-plane zero, and then the original system will obtain open-loop stabilization after it is in series with the NNGI system. The NNGI open-loop control diagram is shown in Figure 4.

3.3. Profibus-DP Network Delay. Profibus communication uses the main token polling mechanism; each site on the bus connects with another in the bus way. Master station is composed of control center such as computer and PLC, while slave station consists of actuators such as inverter and sensors. Each site on the Profibus has its own logical address; a loop called logical loop is formed between the master stations. A token generated during the operation of the frame will poll along the logical link between the master stations. One master station is allowed to poll along other slave stations only when a token reaches this master station, and then the data transmission will be finished. While the process from sending task information of site to receiving the task information by 


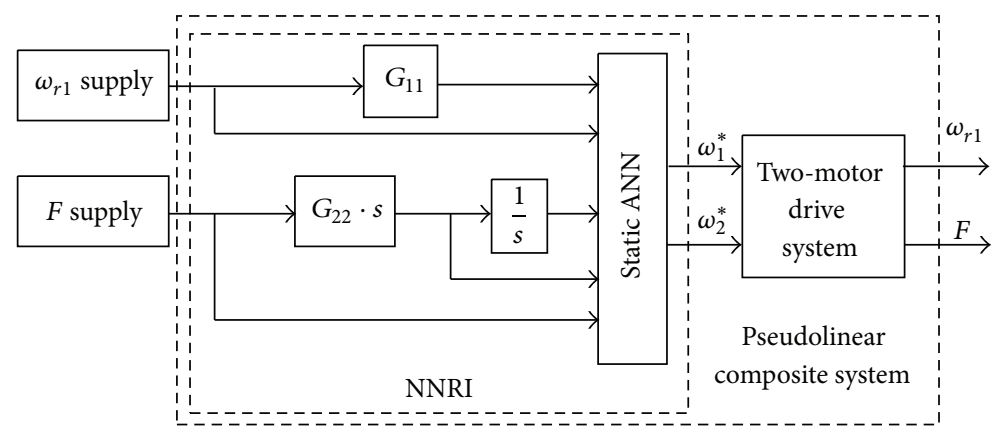

FIGURE 4: NNGI open-loop control diagram.

target is too time intensive, the Profibus-DP network delay is generated.

Profibus-DP network delay is indeterminate in practice. However the maximum delay can be calculated and it can be a reference for the delay of ideal internal model $e^{-m s}[23,24]$. The approximate expression can be written as

$$
R_{h}=B+\operatorname{int}\left[\frac{n_{h}}{(n+1)}\right] \cdot\left(T_{\mathrm{TR}}+T_{\mathrm{chm}}+\tau\right)+\xi_{h}
$$

where $B$ stands for the longest initial blocking, $n_{h}$ is the number of high priority request messages added to the outgoing queue at critical instant, $T_{\mathrm{TR}}$ is the target token rotation time, $T_{\mathrm{chm}}$ is the maximum time of executing a high priority message transmission, $\tau$ is the token latency, $n+1$ is the number of high priority messages which are transmitted during the maximum token holding time, and $\xi_{h}$ is the time between the finish of the last maximum token holding time and the end of target message transmission. There are three possible cases and the expression can be written as

$$
\xi_{h}= \begin{cases}-\tau, & n_{h}=\operatorname{int}\left[\frac{n_{h}}{n+1}\right] \cdot(n+1), \\ T_{\text {chm }}, & n_{h}=\operatorname{int}\left[\frac{n_{h}}{n+1}\right] \cdot(n+1)+1, \\ \left(n_{h}-\operatorname{int}\left[\frac{n_{h}}{n+1}\right] \cdot(n+1)\right) \cdot T_{\mathrm{chm}}+\tau, & n_{h}>\operatorname{int}\left[\frac{n_{h}}{n+1}\right] \cdot(n+1)+1 .\end{cases}
$$

3.4. SIM Control. According to the previous discussions, two-motor drive system is a time-varying delay system. In order to settle the time delay issue, a SIM control is introduced into the controller design. The SIM control incorporates the advantages of Smith estimate control and internal model control. This control strategy is a delay compensation method, which is to separate the delay part of controlled object and connect in series with the system transfer function. It is an effective way to inhibit the effect of time delay. Moreover, SIM control can also restrain the influence of unmeasured disturbances and improve system robustness.

The structure of the SIM control is shown in Figure 5, in which $G_{P}(s)$ and $G_{m}(s)$ are the actual object model and the prediction internal model, respectively. $e^{-P s}$ and $e^{-m s}$ are the related delay of controlled object and prediction internal model, respectively. $G_{c}(s)$ is the controller. $D(s)$ is the external disturbance. $R(s)$ and $Y(s)$ are the input and the output of the system, respectively.

3.4.1. Delay Compensation Analysis. According to Figure 5, the output can be written as

$Y(s)$

$$
=\frac{G_{c}(s) G_{P}(s) e^{-P s}}{1+G_{c}(s) G_{m}(s)+G_{c}(s)\left[G_{P}(s) e^{-P s}-G_{m}(s) e^{-m s}\right]}
$$

$$
\begin{aligned}
& \cdot R(s) \\
& +\frac{1+G_{c}(s) G_{m}(s)-G_{c}(s) G_{m}(s) e^{-m s}}{1+G_{c}(s) G_{m}(s)+G_{c}(s)\left[G_{P}(s) e^{-P s}-G_{m}(s) e^{-m s}\right]} \\
& \cdot D(s) .
\end{aligned}
$$

The closed-loop transfer function of control system is

$$
\begin{aligned}
& G(s)=\frac{Y(s)}{R(s)} \\
& =\frac{G_{c}(s) G_{P}(s) e^{-P s}}{1+G_{c}(s) G_{m}(s)+G_{c}(s)\left[G_{P}(s) e^{-P s}-G_{m}(s) e^{-m s}\right]} .
\end{aligned}
$$

When the prediction internal model is accurate, $G_{m}(s) e^{-m s}$ is equal to $G_{P}(s) e^{-P s}$, and the transfer function can be written as

$$
G(s)=\frac{G_{c}(s) G_{P}(s)}{1+G_{c}(s) G_{P}(s)} e^{-P s} .
$$

Hence, there is no delay part in the denominator of closedloop transfer function and the delay is totally compensated. 


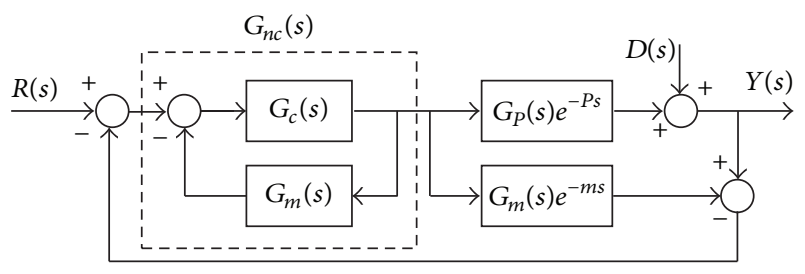

FIGURE 5: SIM control diagram.

3.4.2. Fixed Value Tracking Ability. According to Figure 5, when the external disturbance $D(s)$ is zero, then the error of closed-loop system can be written as

$$
\begin{aligned}
E(s) & =R(s)-Y(s) \\
& =\frac{1-G_{n c}(s) G_{m}(s) e^{-m s}}{1+G_{n c}(s)\left(G_{P}(s) e^{-P s}-G_{m}(s) e^{-m s}\right)} R(s) .
\end{aligned}
$$

In consideration of modeling error of actual system, the controlled object can be described with multiplicative uncertainty:

$$
G_{P}(s) e^{-P s}=G_{m}(s) e^{-m s}\left(1+l_{m}(s)\right),
$$

where $l_{m}(s)$ represents the uncertainty and it is bounded.

The structure in dashed box is represented by $G_{n c}(s)$. A low pass filter is added to improve the capacity of resisting disturbance. The filter is represented as $F(s)$, and then $G_{n c}(s)$ can be written as

$$
G_{n c}(s)=G_{m}^{-1}(s) F(s) .
$$

Therefore, the transfer function of low pass filter is

$$
F(s)=\frac{1}{(\lambda s+1)^{n}},
$$

where $\lambda$ describes filter parameter and $n$ stands for the order of filter.

Then, the error of closed-loop system can be simplified as

$$
E(s)=\frac{(\lambda s+1)^{n}-e^{-m s}}{(\lambda s+1)^{n}+l_{m}(s) e^{-m s}} R(s) .
$$

The limit of $l_{m}(s)$ can be expressed as

$$
\lim _{s \rightarrow 0} l_{m}(s)=C,
$$

where $C$ is a constant.

When the input signal is step signal,

$$
R(s)=\frac{R_{0}}{s},
$$

then, the limit of $E(s)$ is

$$
\begin{aligned}
e(\infty) & =\lim _{s \rightarrow 0} s E(s) \\
& =\lim _{s \rightarrow 0} s\left(\frac{(\lambda s+1)^{n}-e^{-m s}}{(\lambda s+1)^{n}+l_{m}(s) e^{-m s}} \cdot \frac{R_{0}}{s}\right)=0 .
\end{aligned}
$$

3.4.3. Anti-Interference Ability. According to Figure 5, when the input $R(s)$ is zero, then the error of closed-loop system can be written as

$$
\begin{aligned}
E(s) & =R(s)-Y(s) \\
= & \frac{1-G_{n c}(s) G_{m}(s) e^{-m s}}{1+G_{n c}(s)\left(G_{P}(s) e^{-P s}-G_{m}(s) e^{-m s}\right)}(-D(s)) .
\end{aligned}
$$

Similar to the analysis of fixed value tracking ability, the error of closed-loop system can be simplified as

$$
E(s)=\frac{(\lambda s+1)^{n}-e^{-m s}}{(\lambda s+1)^{n}+l_{m}(s) e^{-m s}}(-D(s)) .
$$

When the external disturbance is step signal,

$$
D(s)=\frac{D_{0}}{s}
$$

then, the limit of $E(s)$ is

$$
\begin{aligned}
e(\infty) & =\lim _{s \rightarrow 0} s E(s) \\
& =\lim _{s \rightarrow 0} s\left(-\frac{(\lambda s+1)^{n}-e^{-m s}}{(\lambda s+1)^{n}+l_{m}(s) e^{-m s}} \cdot \frac{D_{0}}{s}\right)=0 .
\end{aligned}
$$

In conclusion, the SIM control structure can satisfactorily solve delay problem. What is more, this control structure also has good input signal tracking ability and anti-interference ability.

3.5. NNGI-SIM Control. As mentioned above, SIM control can remove the delay of forward network from the closedloop and set it as a gain block before the output. As a result, the delay on the return network path can be totally eliminated. Meanwhile, SIM control can also enhance robustness and anti-interference ability of the system with the internal model control structure. However, the accuracy of prediction model $G_{m}(s)$ is crucial. When there is a mismatch between prediction model and actual model, the control quality will be significantly deteriorated. This problem can be solved by NNGI system. After connecting with NNGI system, the original system is decoupled into two subsystems, namely, a first-order speed one and a second-order tension one. The accurate mathematical model of two subsystems can be obtained after pole-zero allocation of the pseudolinear subsystems, and then the internal model can be predicted. Then, the mismatch condition will be avoided. The diagram of NNGI-SIM control strategy of the two-motor drive system is shown in Figure 6.

In Figure 5, the function of the construction in dashed box can be expressed as

$$
G_{n c}(s)=\frac{G_{c}(s)}{1+G_{c}(s) G_{m}(s)} .
$$

According to (22) and (32), $G_{c}(s)$ can be calculated as

$$
G_{c}(s)=\frac{G_{m}^{-1}(s) F(s)}{1-F(s)} .
$$




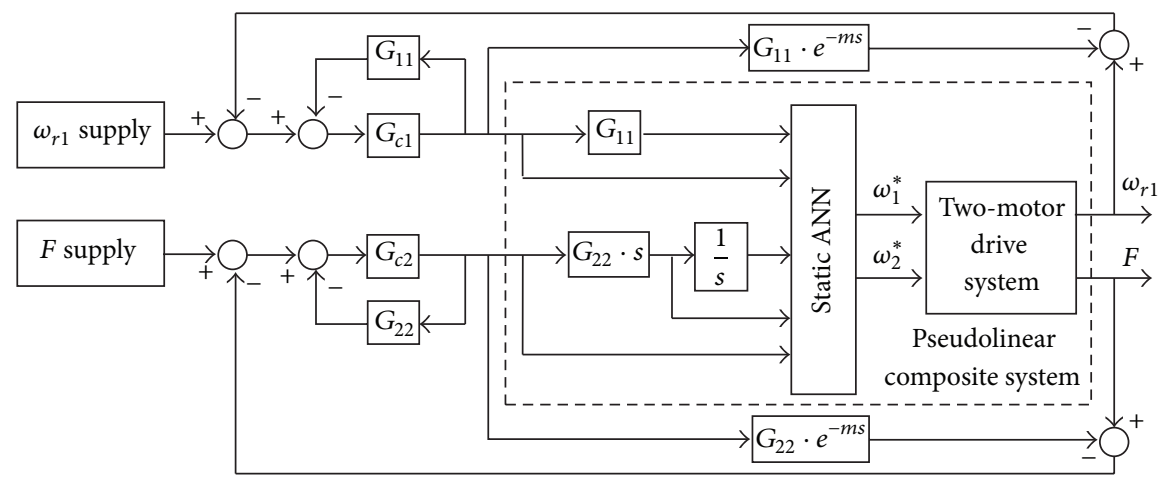

FIGURE 6: NNGI-SIM control diagram.

In a two-motor NNGI system, the original system is separated into two subsystems. For the speed subsystem, the transfer function is $G_{11}=1 /(s+1)$ and the order of filter $n$ is one. The expression of $G_{c 1}(s)$ can be transformed into the structure of classical PI controller, in which $K_{P 1}$ is $1 / \lambda_{1}$ and $T_{I 1}$ is 1 . According to (23) and (33), $G_{c 1}(s)$ can be written as

$$
G_{c 1}(s)=\frac{G_{11}^{-1}(s) F_{1}(s)}{1-F_{1}(s)}=\frac{1}{\lambda_{1}}\left(1+\frac{1}{s}\right) .
$$

For the tension subsystem, according to (14), the transfer function is $G_{22}=1 /\left(s^{2}+1.414 s+1\right)$ and the order of filter $n$ is one; then $G_{c 2}(s)$ can be written as

$$
G_{c 2}(s)=\frac{G_{22}^{-1}(s) F_{2}(s)}{1-F_{2}(s)}=\frac{s^{2}+1.414 s+1}{\lambda_{2} s} .
$$

The expression of $G_{c 2}(s)$ can be transformed into the structure of classical PID controller:

$$
G_{c 2}(s)=\frac{1.414}{\lambda_{2}}\left(1+\frac{1}{1.414 s}+\frac{1}{1.414} s\right),
$$

where $K_{P 2}$ is $1.414 / \lambda_{2}, T_{I 2}$ is 1.414 , and $T_{D 2}$ is $1 / 1.414$.

\section{Simulation}

4.1. Procedure of Simulation. In order to verify the decoupling ability of the proposed NNGI system, feed-forward neural network is adopted to approximate inversion system. The design procedure of NNGI pseudolinear composite system is briefly given as follows.

4.1.1. Sample Collection. Since the parameters of the original system model are unknown or variable, the selected signals should stimulate the dynamic and static characters of original system sufficiently. So, the square wave signal is chosen to verify dynamic performance of the proposed motor drive in each frequency band. Differentiators in the NNGI system can be obtained by using five-point numerical derivative algorithm, in which high computing accuracy is offered. The speed value ranges from $100 \mathrm{r} / \mathrm{min}$ to $600 \mathrm{r} / \mathrm{min}$ and tension value ranges from $100 \mathrm{~N}$ to $600 \mathrm{~N}$.
4.1.2. Neural Network Training. According to (12), $\left\{y_{1}, y_{1}+\right.$ $\left.\dot{y}_{1}, y_{2}, \dot{y}_{2}, \ddot{y}_{2}+1.414 \dot{y}_{2}+y_{2}\right\}$ are chosen as the input and $u$ is chosen as the output to train the NNGI system. Before training neural network, the sampled data should be normalized and break off both ends to improve convergence precision. Furthermore, the neural network adopts 5-15-2 3-layer structure; the activation functions of hidden layer and output layer choose tansig and pureline functions, respectively. The weight and the threshold of the neural network should be adjusted by using the Levenberg-Marquardt algorithm until convergence precision attains the expectant effect. The output of neural network should be antinormalized back to the original range. Then, the training of NNGI system is over.

4.1.3. Integration of Pseudolinear Composite System. After putting the NNGI system in front of the original system, the pseudolinear composite system is constructed. A strong coupling and nonlinear system is separated into two pseudolinear composite subsystems. By adopting the SIM control structure, two independent control loops are formed to achieve the aim of decoupling control.

A MIMO nonlinear system is decoupled by NNGI method, and then the accurate model of generalized pseudolinear subsystem can be obtained, in which the controllers' parameters depend on the accurate mathematical model. The robustness of the controllers is mainly determined by the filters, and the first-order filter is considered as the best controller. After a lot of simulation experiments, the filter parameters $\lambda_{1}$ and $\lambda_{2}$ are chosen to be 0.2 and 1.2, respectively, and then the filters can meet the system requirements. Hence, the controller parameters of two pseudolinear subsystems can be optimized. According to the analysis of previous discussions, the expressions of $G_{c 1}$ and $G_{c 2}$ can be written as the classical PID controller. According to (34) and (36), $K_{P 1}$ is 5 and $T_{I 1}$ is 1 in the speed subsystem, $K_{P 2}$ is $1.2, T_{I 2}$ is 0.8 , and $T_{D 2}$ is 0.8 in the tension subsystem. The simulation model is developed according to Figure 6. Based on the NNGI-SIM control strategy, the coupling issue can be settled and the delay of Profibus-DP network can also be compensated.

4.2. Comparative Discussions. In order to evaluate the proposed NNGI-SIM control system, $\omega_{r 1}$ is set to track square 


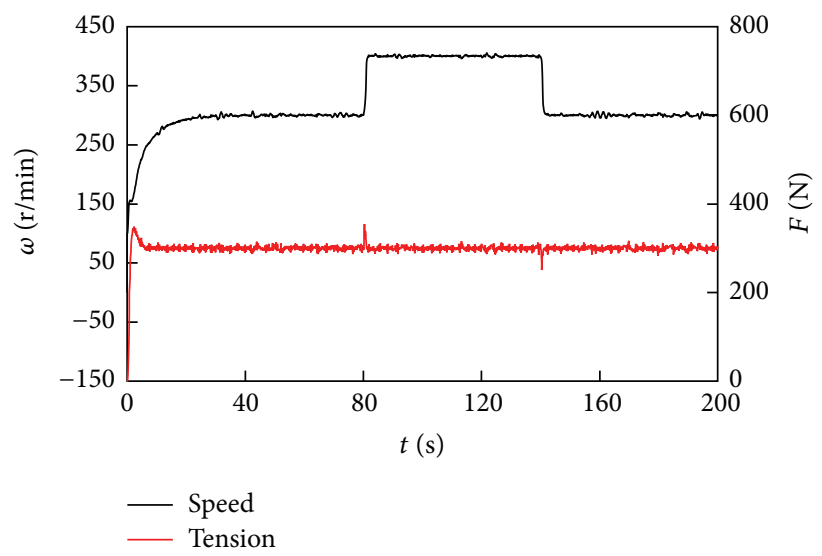

(a) PID control strategy

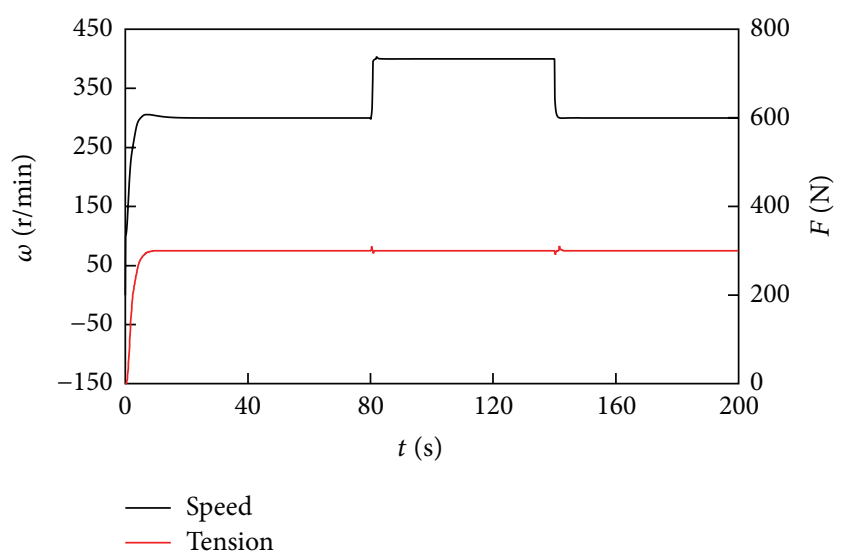

(b) NNGI-SIM control strategy

FIGURE 7: Simulated responses when $\omega_{r 1}$ suddenly changes.

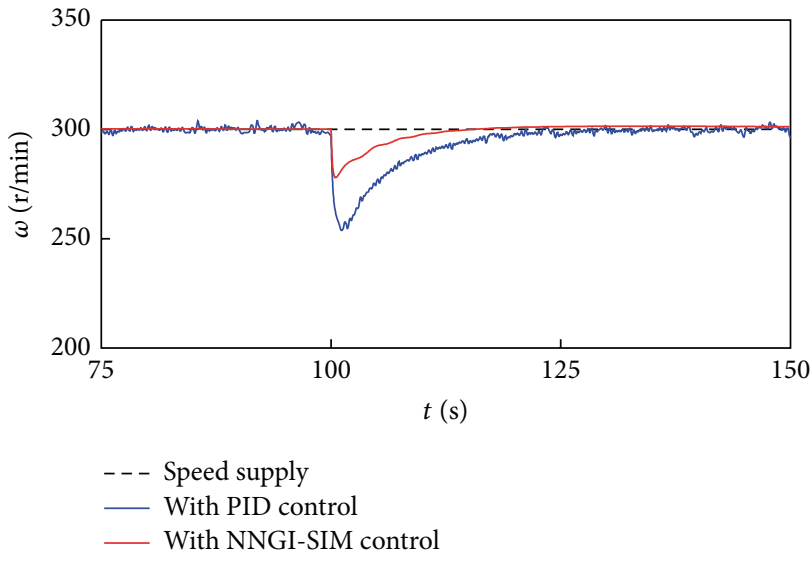

(a) Speed responses

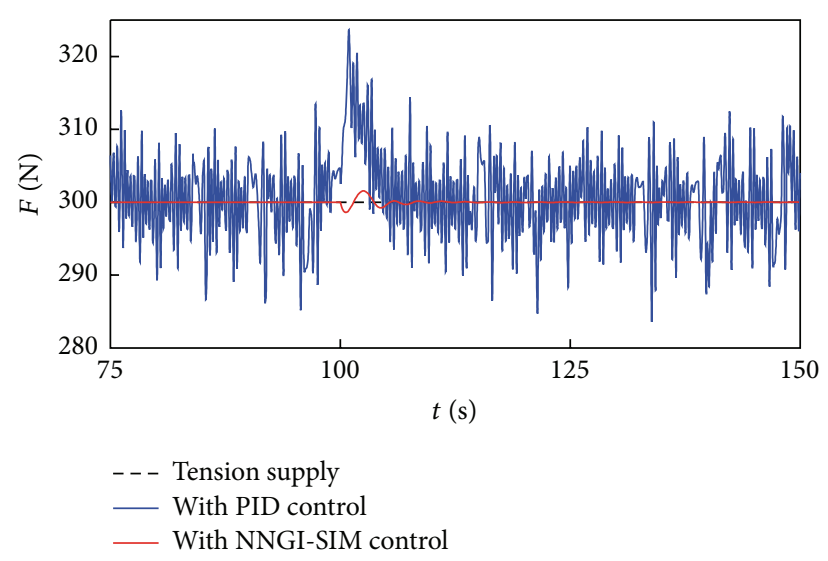

(b) Tension responses

FIGURE 8: Simulated responses for sudden increased load impact.

wave response and $F$ is set to constant 300 N. $\omega_{r 1}$ increases from $200 \mathrm{r} / \mathrm{min}$ to $250 \mathrm{r} / \mathrm{min}$ at $80 \mathrm{~s}$ and decreases from $250 \mathrm{r} / \mathrm{min}$ to $200 \mathrm{r} / \mathrm{min}$ at $140 \mathrm{~s}$. As shown in Figure 7, due to the effect of system delay, the responses of traditional PID control have high frequency shiver during the whole simulation. Large fluctuations of the tension responses occur at the constant of speed sudden changing. Therefore, it cannot effectively decouple speed and tension. Moreover, the response speed is slow and transient time is too long. By contrast, with the NNGI-SIM control structure, the shiver problem has been solved. Furthermore, the tension fluctuation caused by the sudden change of speed is restrained to a great extent. The disturbance caused by speed impact is significantly reduced. Hence, this two-motor system is effectively coupled; the speed of motors and tension will not be influenced by each other.

In order to evaluate the restraining disturbance ability of the proposed control strategy, $\omega_{r 1}$ and $F$ are set to be constants of $300 \mathrm{r} / \mathrm{min}$ and $300 \mathrm{~N}$, respectively. Figure 8 is the sudden load increase from $2 \mathrm{Nm}$ to $5 \mathrm{Nm}$ at $100 \mathrm{~s}$, while Figure 9 is the sudden load decrease from $5 \mathrm{Nm}$ to $2 \mathrm{Nm}$ at $100 \mathrm{~s}$. At the PID control operation, speed and tension have large fluctuations and both of them are significantly affected by load jump. In contrast, at the proposed control operation, the fluctuation of speed is smoothed and tension is immune to this load change, indicating that the proposed system has a strong antidisturbance ability. Furthermore, the fluctuation issue caused by transmission delay has been settled completely. Since SIM control structure can separate the delay part of controlled object and connect in series with the system transfer function, the operation of system is immune to delay. So, the tension responses by NNGI-SIM control are relatively smooth and the delay of SIM control structure is obviously compensated.

\section{Experimental Verification}

The experimental platform of multimotor drive system is designed as shown in Figure 10, by which the number of the test motors can be up to three. The whole system includes industrial computer, Siemens S7-300 PLC, Siemens micromaster vector inverters, $2.2 \mathrm{~kW}$ three-phase asynchronous 


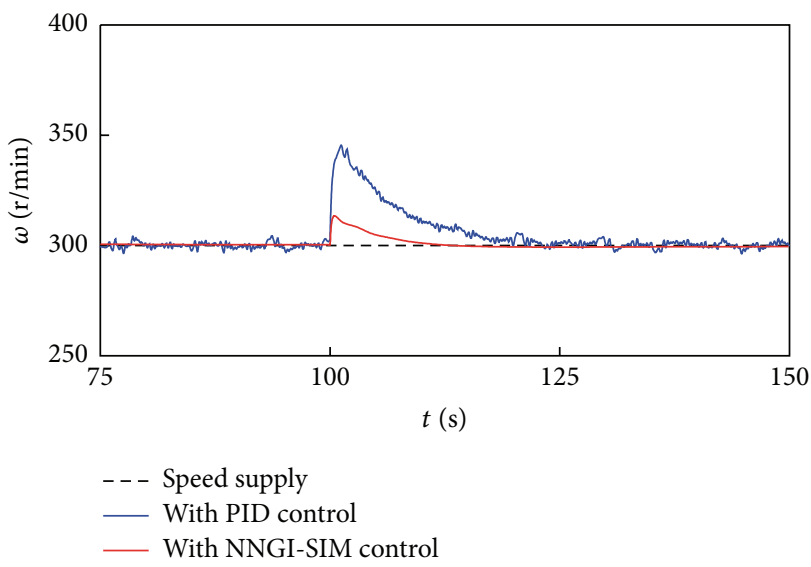

(a) Speed responses

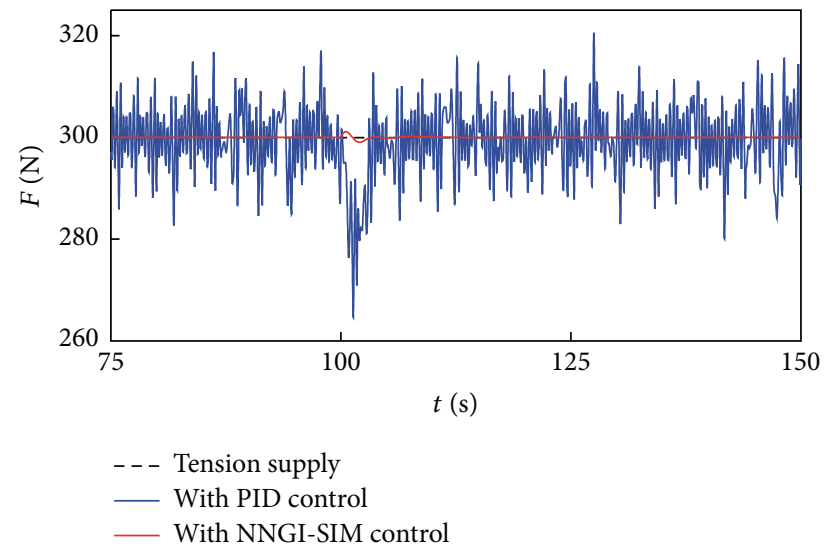

(b) Tension responses

FIGURE 9: Simulated responses for sudden decreased load impact.

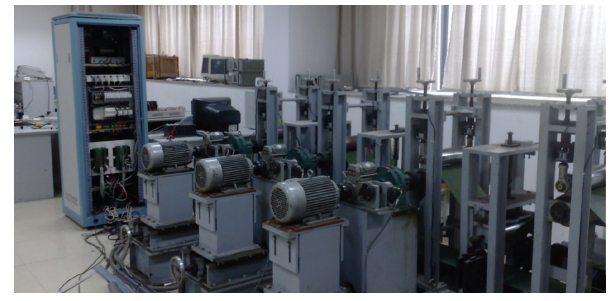

Figure 10: Experimental platform.

motors, photoelectric encoder, magnetic powder brakes, and tension sensor.

In the experimental platform, S7-300 PLC is the main controller which sends the frequency signal to the inverters. In addition, the inverters drive motors in vector control mode and the motors connect conveyor belt with roller.

The PLC controls two inverters through Profibus-DP communication which is the main way of message transmission delay. According to (15) and (16), this study sets the data transfer rate of Profibus-DP network as $1.5 \mathrm{Mbps}$, and then the data bit period is equal to 0.667 us. Besides, $n_{h}$ is chosen to be 20 and $T_{\mathrm{TR}}$ is fixed to $8 \mathrm{~ms}$, and then $B$ is equal to $2.18 \mathrm{~ms}$, $T_{\text {chm }}$ is equal to $1.27 \mathrm{~ms}, \tau$ is approximately equal to $0.04 \mathrm{~ms}$, $n$ is equal to 6 , and $\xi_{h}$ is equal to $7.66 \mathrm{~ms}$ in the third case.

Hence, according to (15), the maximum delay of ProfibusDP network is

$$
\begin{aligned}
R_{h} & =B+\text { int }\left[\frac{n_{h}}{n+1}\right] \cdot\left(T_{\mathrm{TR}}+T_{\mathrm{chm}}+\tau\right)+\xi_{h} \\
& =28.46 \mathrm{~ms} .
\end{aligned}
$$

The hardware experiment condition is similar to simulation one, of which the procedure can be divided into three parts, namely, sample collection, training offline, and control implementation. However, differently, the experimental motor will be affected by external disturbances and mechanical vibration, hence resulting in the fluctuations of response speed and tension. To eliminate these harmful effects, antipulse interference average filter is applied to filter the real-time sampled signals. This filter method collects $N$ sets of date continually, removes the maximum and the minimum, and takes the average of the remaining date as the output of the filter. The feedback signal after filtering has no significant fluctuation and is smooth. It is conducive to improve curve-fitting condition and convergence precision in neural network training.

This work implements the feed-forward neural networks with instruction list of Siemens PLC. After transferring the trained weights and thresholds to the corresponding register units, the NNGI system is accomplished in S7-300 PLC platform. Then, by adopting the SIM control structure to deal with the problem of Profibus-DP network delay, the whole closed-loop system is formed.

In order to verify the decoupling effectiveness, the tension supply of $300 \mathrm{~N}$ is chosen and the speed supply is set to suddenly change from $300 \mathrm{r} / \mathrm{min}$ to $400 \mathrm{r} / \mathrm{min}$. The responses of the experiment system with PID control and with NNGI-SIM control are compared in Figure 11. As shown in Figure 11(a), the tension response fluctuates dramatically when the speed suddenly changes. Thus, the strong coupling problem cannot be solved by the traditional PID control. Moreover, the transmission delay leads to the fluctuation of responses, which agrees with the simulated one. Comparatively, in Figure 11(b), with the sudden change of speed from $300 \mathrm{r} / \mathrm{min}$ to $400 \mathrm{r} / \mathrm{min}$ at $80 \mathrm{~s}$, the jitter has been reduced, so the sudden change of speed has less influence on tension response. It is obvious that the tension and the speed are successfully decoupled by using the proposed control strategy. Hence, the NNGI-SIM control is superior to PID control in the twomotor drive system with network delay.

The measured responses of speed and tension under sudden load impact are shown in Figures 12 and 13. In Figure 12, the motor starts at no load and then increases to $3 \mathrm{Nm}$ suddenly. By contrast, in Figure 13, the load decreases from $3 \mathrm{Nm}$ to $0 \mathrm{Nm}$.

As shown in Figures 12 and 13, the proposed control strategy reduces the impact on speed and tension caused by the sudden application of load. The fluctuation of tension is mitigated effectively under NNGI-SIM control. However, 


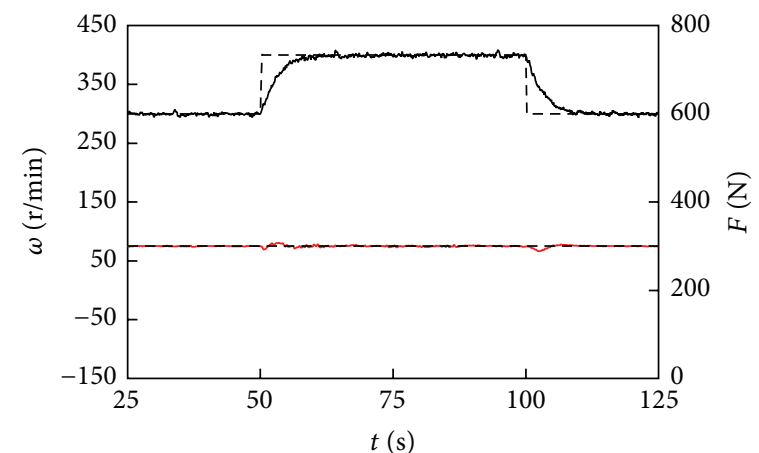

- Speed

(a) PID control strategy

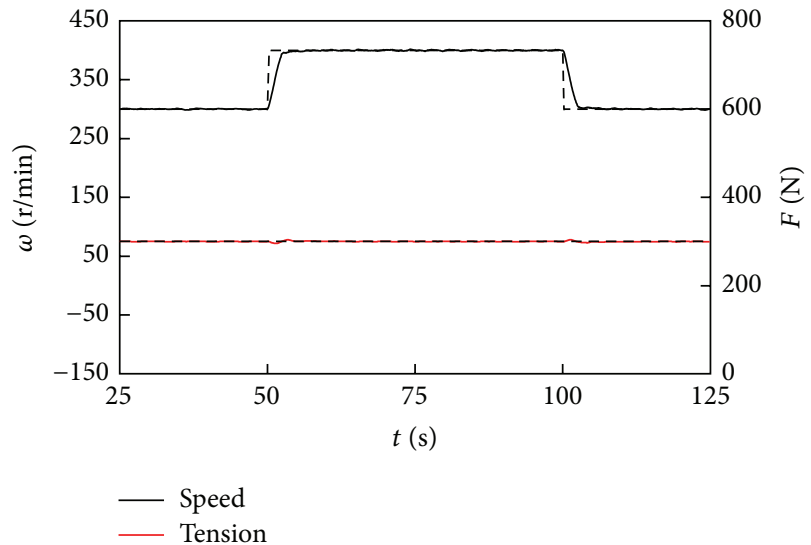

(b) NNGI-SIM control strategy

FIGURE 11: Experimental results when $\omega_{r 1}$ suddenly changes.

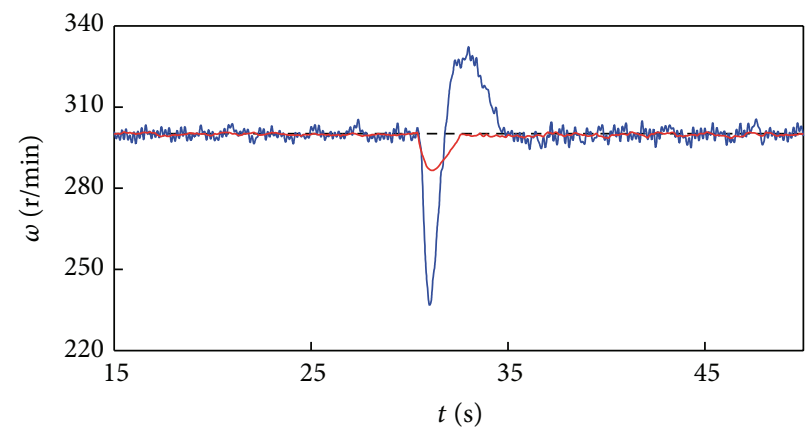

- - - Speed supply

— With PID control

— With NNGI-SIM control

(a) Speed responses

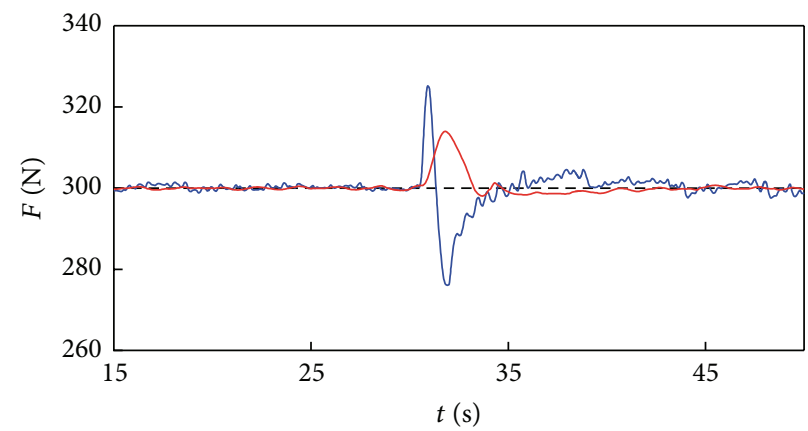

- - - Tension supply

— With PID control

_ With NNGI-SIM control

(b) Tension responses

FIGURE 12: Experimental results for sudden increased load impact.
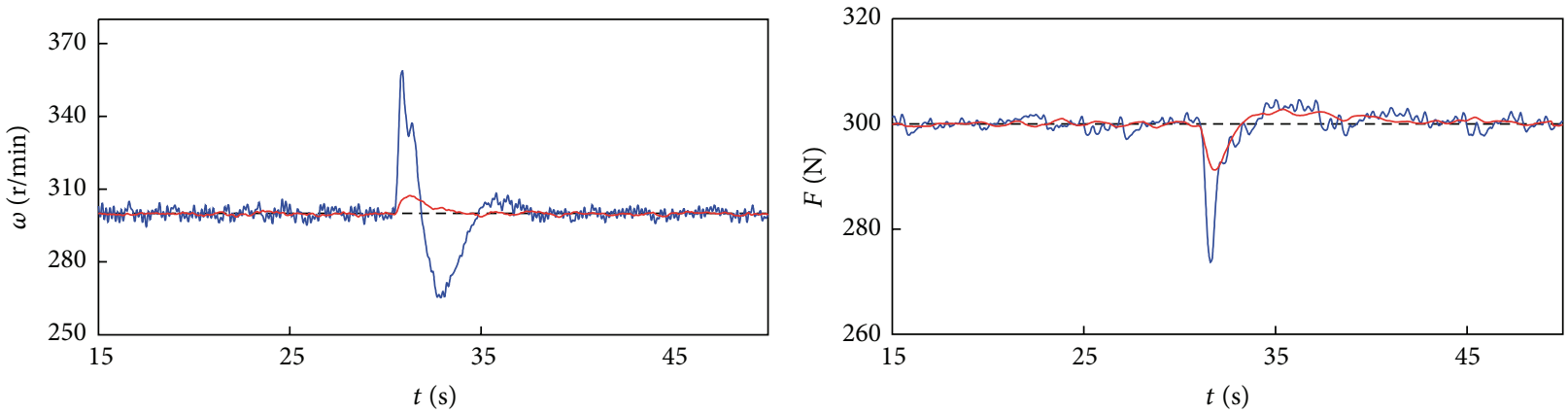

\section{- - - Speed supply \\ — With PID control \\ — With NNGI-SIM control}

(a) Speed responses
- - - Tension supply

— With PID control

With NNGI-SIM control

FIGURE 13: Experimental results for sudden decreased load impact. 
the improvement of speed response is relatively less because the magnetic powder brake has direct effects on motor shaft. Overall, the NNGI-SIM control strategy achieves the good dynamic and static performances, and it has strong robustness to the load disturbances.

\section{Conclusion}

In this paper, a new control strategy has been proposed to solve the Profibus-DP network delay problem and decouple the speed and the tension of the two-motor drive system by incorporating NNGI and SIM control. The NNGI strategy has been used to transform the MIMO two-motor drive system to several single-input single-output systems, and then the speed and tension are decoupled validly. By adopting the SIM control structure to compose a closed-loop system, the delay issue has been compensated. The designed system can provide good starting and tracking capabilities. The utilities of the proposed control strategy have been verified by both the simulation and the experiments at various operations. The proposed control strategy has a great application prospect in the field of multimotor control system.

\section{Conflict of Interests}

The authors declare that there is no conflict of interests regarding the publication of this paper.

\section{Acknowledgments}

This work was supported by the National Natural Science Foundation of China (51277194 and 61273154), by the Key Project of Natural Science Foundation of Jiangsu Higher Education Institutions (15KJA470002), by the Research Fund for 333 Project of Jiangsu Province (BRA2015302), and by the Priority Academic Program Development of Jiangsu Higher Education Institutions.

\section{References}

[1] R. Cao, C. Mi, and M. Cheng, "Quantitative comparison of fluxswitching permanent-magnet motors with interior permanent magnet motor for EV, HEV, and PHEV applications," IEEE Transactions on Magnetics, vol. 48, no. 8, pp. 2374-2384, 2012.

[2] G. Liu, J. Yang, W. Zhao, J. Ji, Q. Chen, and W. Gong, "Design and analysis of a new fault-tolerant permanent-magnet vernier machine for electric vehicles," IEEE Transactions on Magnetics, vol. 48, no. 11, pp. 4176-4179, 2012.

[3] Y. Du, K. T. Chau, M. Cheng, Y. Wang, and J. Li, "A linear doubly-salient HTS machine for wave energy conversion," IEEE Transactions on Applied Superconductivity, vol. 21, no. 3, pp. 1109-1113, 2011.

[4] W. Zhao, M. Cheng, J. Ji, R. Cao, Y. Du, and F. Li, "Design and analysis of a new fault-tolerant linear permanent-magnet motor for maglev transportation applications," IEEE Transactions on Applied Superconductivity, vol. 22, no. 3, 2012.

[5] W.-B. Lin, C.-A. Chen, and H.-K. Chiang, "Design and implementation of a sliding mode controller using a Gaussian radial basis function neural network estimator for a synchronous reluctance motor speed drive," Electric Power Components and Systems, vol. 39, no. 6, pp. 548-562, 2011.
[6] R.-L. Lin, P.-Y. Yeh, and C.-H. Liu, "Positive feed-forward control scheme for distributed power conversion system with multiple voltage sources," IEEE Transactions on Power Electronics, vol. 27, no. 7, pp. 3186-3194, 2012.

[7] R. H. Du, Y. F. Wu, W. Chen, and Q. Chen, "Adaptive fuzzy speed control for permanent magnet synchronous motor servo systems," Electric Power Components and Systems, vol. 42, no. 8, pp. 798-807, 2014.

[8] G. Liu, L. Chen, W. Zhao, Y. Jiang, and L. Qu, "Internal model control of permanent magnet synchronous motor using support vector machine generalized inverse," IEEE Transactions on Industrial Informatics, vol. 9, no. 2, pp. 890-898, 2013.

[9] G. Liu, K. Yu, and W. Zhao, "Neural network based internal model decoupling control of three-motor drive system," Electric Power Components and Systems, vol. 40, no. 14, pp. 1621-1638, 2012.

[10] D. Yu, F. Liu, P.-Y. Lai, and A. Wu, "Nonlinear dynamic compensation of sensors using inverse-model-based neural network," IEEE Transactions on Instrumentation and Measurement, vol. 57, no. 10, pp. 2364-2376, 2008.

[11] Y. Zhang, D. Guo, and Z. Li, "Common nature of learning between back-propagation and hopfield-type neural networks for generalized matrix inversion with simplified models," IEEE Transactions on Neural Networks and Learning Systems, vol. 24, no. 4, pp. 579-592, 2013.

[12] L. Guo and L. Parsa, "Model reference adaptive control of fivephase IPM motors based on neural network," IEEE Transactions on Industrial Electronics, vol. 59, no. 3, pp. 1500-1508, 2012.

[13] C. B. Butt and M. A. Rahman, "Untrained artificial neuronbased speed control of interior permanent-magnet motor drives over extended operating speed range," IEEE Transactions on Industry Applications, vol. 49, no. 3, pp. 1146-1153, 2013.

[14] T.-C. Chen and C.-H. Yu, "Generalized regression neuralnetwork-based modeling approach for traveling-wave ultrasonic motors," Electric Power Components and Systems, vol. 37, no. 6, pp. 645-657, 2009.

[15] S. A. R. Kashif and M. A. Saqib, "Sensorless control of a permanent magnet synchronous motor using artificial neural network based estimator-an application of the four-switch three-phase inverter," Electric Power Components and Systems, vol. 42, no. 1, pp. 1-12, 2014.

[16] S. Alcántara, A. Ibeas, J. A. Herrera, R. Vilanova, and C. Pedret, "Multi-model smith predictor based control of multivariable systems with uncertain bounded external delays," IEEE Latin America Transactions, vol. 7, no. 1, pp. 42-53, 2009.

[17] C.-L. Lai, P.-L. Hsu, and W. X. Zhao, "Design the remote control system with the time-delay estimator and the adaptive smith predictor," IEEE Transactions on Industrial Informatics, vol. 6, no. 1, pp. 73-80, 2010.

[18] D. E. Rivera, M. Morari, and S. Skogestad, "Internal model control: PID controller design," Industrial \& Engineering Chemistry Process Design and Development, vol. 25, no. 1, pp. 252-265, 1986.

[19] C. Xia, Y. Yan, P. Song, and T. Shi, "Voltage disturbance rejection for matrix converter-based PMSM drive system using internal model control," IEEE Transactions on Industrial Electronics, vol. 59, no. 1, pp. 361-372, 2012.

[20] S. Li and H. Gu, "Fuzzy adaptive internal model control schemes for PMSM speed-regulation system," IEEE Transactions on Industrial Informatics, vol. 8, no. 4, pp. 767-779, 2012. 
[21] X. Wei, K. M. Tsang, and W. L. Chan, "DC/DC buck converter using internal model control," Electric Power Components and Systems, vol. 37, no. 3, pp. 320-330, 2009.

[22] X. Z. Dai, D. He, T. Zhang, and K. Zhang, "ANN generalised inversion for the linearisation and decoupling control of nonlinear systems," IEE Proceedings: Control Theory and Applications, vol. 150, no. 3, pp. 267-277, 2003.

[23] S. Vitturi, "Stochastic model of the profibus DP cycle time," IEE Proceedings-Science, Measurement and Technology, vol. 151, no. 5, pp. 335-342, 2004.

[24] K. C. Lee, S. Lee, and M. H. Lee, "Remote fuzzy logic control of networked control system via Profibus-DP," IEEE Transactions on Industrial Electronics, vol. 50, no. 4, pp. 784-792, 2003. 


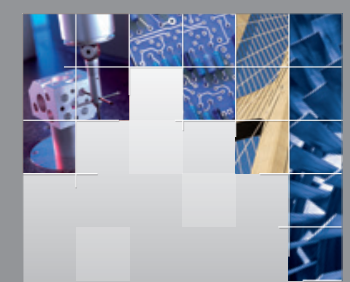

\section{Enfincering}
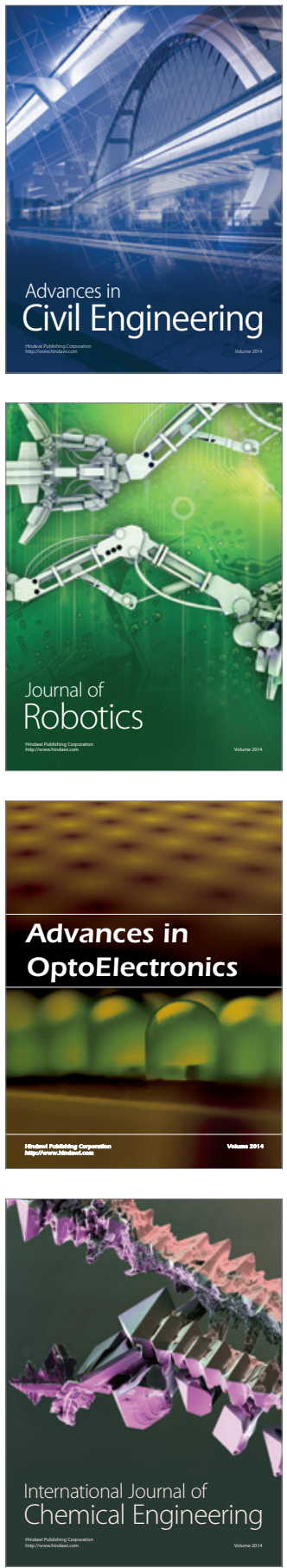

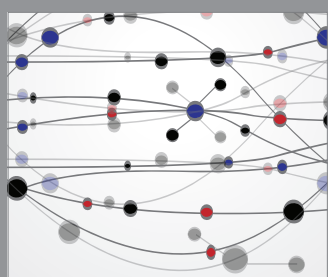

The Scientific World Journal

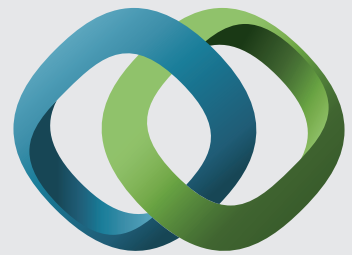

\section{Hindawi}

Submit your manuscripts at

http://www.hindawi.com
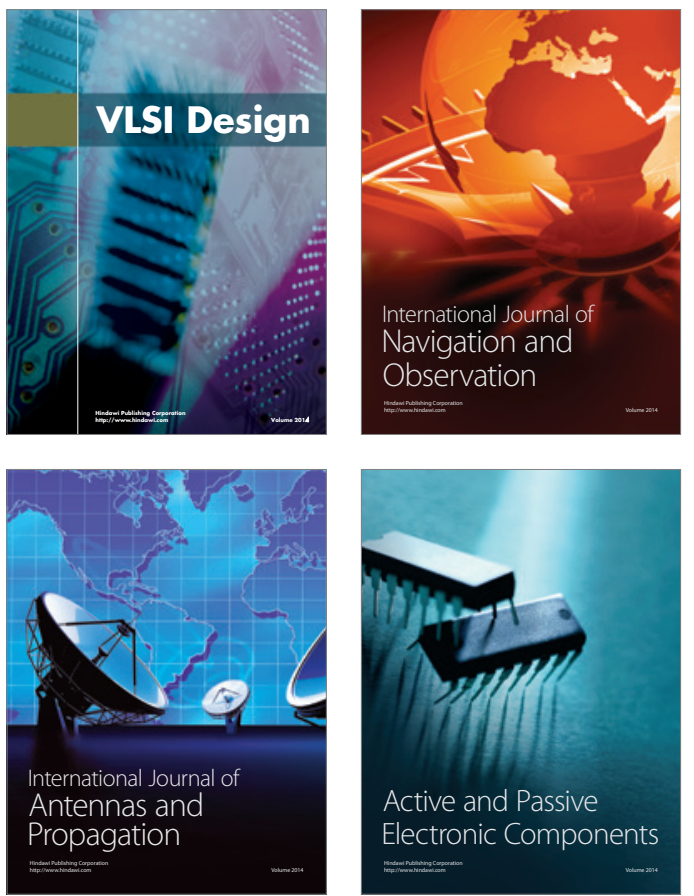
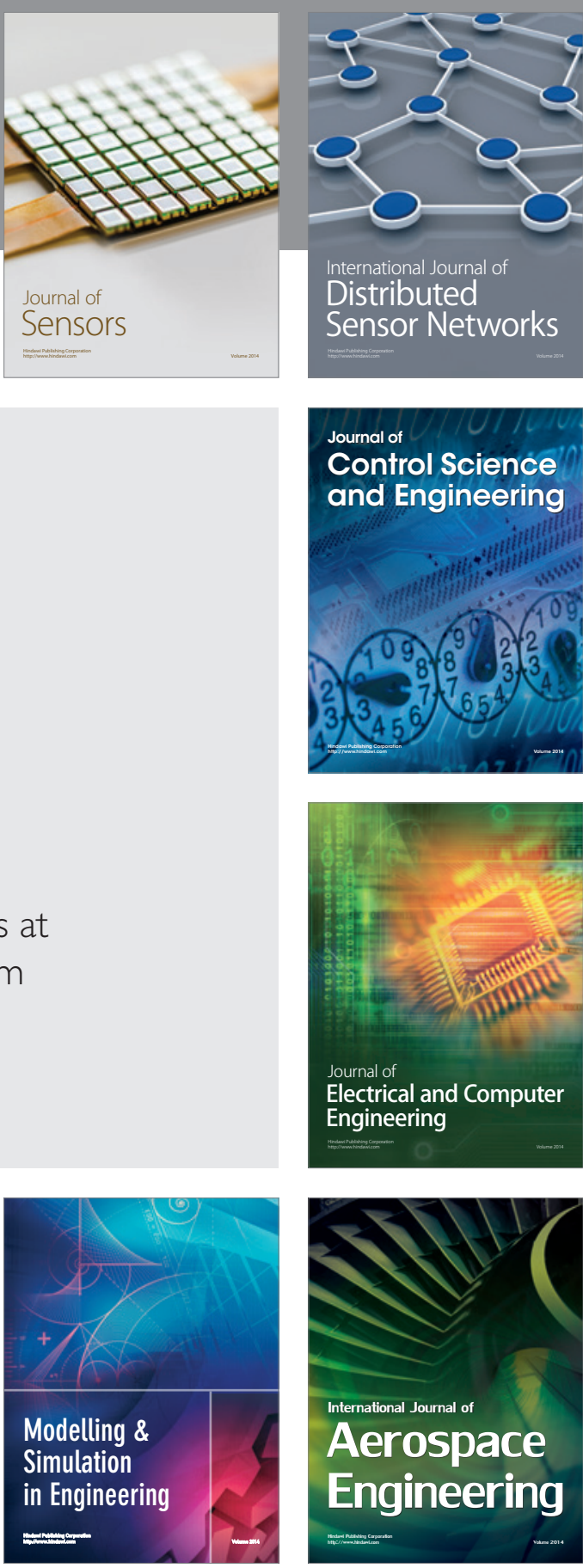

International Journal of

Distributed

Sensor Networks

Journal of

Control Science

and Engineering
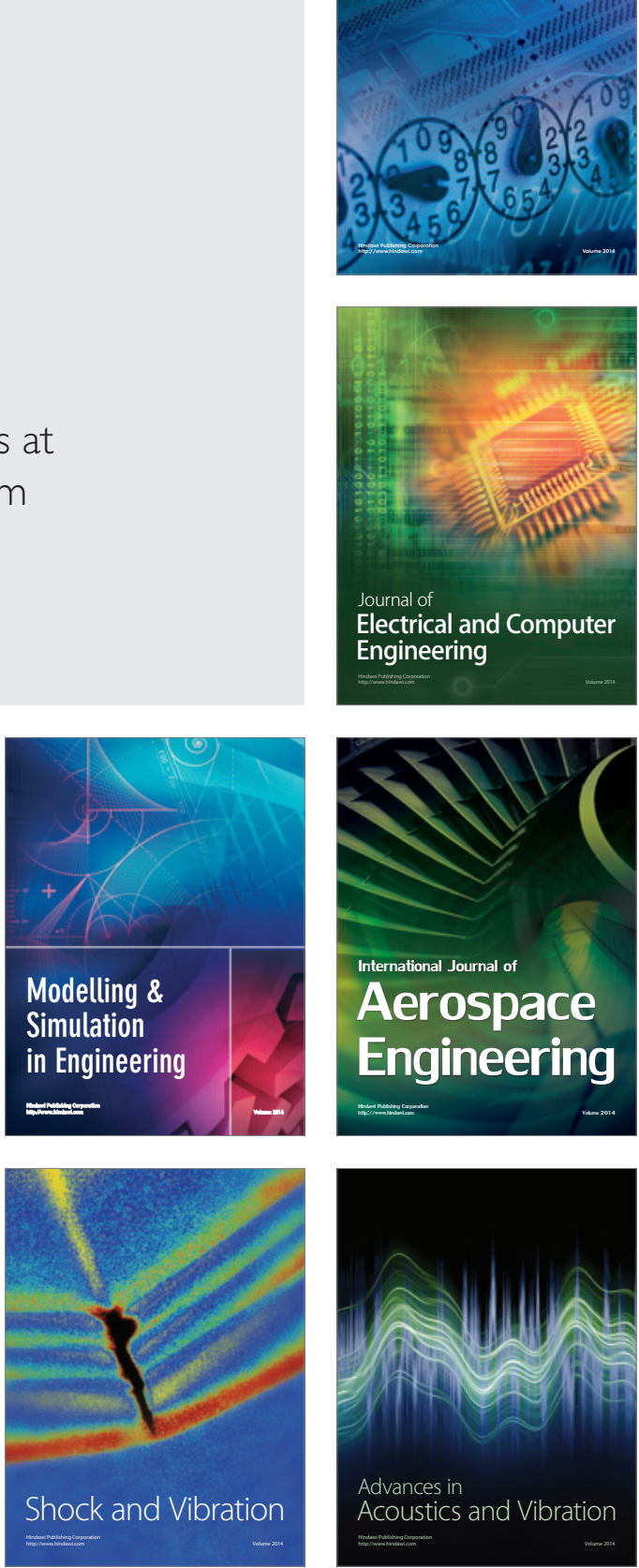